\title{
Disability and Human Supports
}

\author{
Jeff McNair ${ }^{a}$ \\ ${ }^{a}$ PhD, Director Policy Center, Joni and Friends, Christian Institute on Disability; Professor of Special Education, \\ California Baptist University, California, USA
}

\begin{abstract}
This article provides a brief overview of models of disability growing out of the field of disability studies and leading to a call for interventions going beyond a simply medical model approach. A brief discussion of human supports/services is provided such that readers engaged in the development of services/supports can base them on best principles.
\end{abstract}

The profession that individuals with disabilities and their families perhaps look to more than any other is the medical profession. Physicians are seen as those who have the power to cure, to take away or alleviate the impact of someone's disability. In many cases, medical treatments do have the power to change the lives of those served. Yet, probably far more people with disabilities are not cured of their impairments, in spite of professional help. This is a fact that is critical for both physicians and people affected by disability to recognize.

However, there is a great deal that doctors can do. They have influence over patients, families and the community. The goal of this article is to help medical doctors understand the topic of disability and through this understanding, have a greater positive impact on those with disabilities. They may or may not be able to help in the strict medical sense, but as members of the human services community they can influence professionals and local communities for the benefit of people who are affected by disability.

\section{Models of Disability}

Arguably, there are three basic models of disability with many nuanced versions growing out of them which provide a way for us to understand disability. ${ }^{1}$ These models have largely come out of the field of disability studies. The answer to the question, "What is disability?" on its face may seem to be simply answered. For example, the Americans with Disabilities Act, which became law in the United States in 1990, defines a person with a disability as someone who has physical or mental impairment that substantially limits one or more major life activity. ${ }^{2}$ However, the World Health Organization states "Disability is not an attribute of an individual, but rather a complex collection of conditions, many of which are created by the social environment". 3 So in reality it is a question with complex answers. The so called models of disability help us to begin to get our minds around what disability actually is. Let's consider each of these briefly. 


\section{The Moral Model}

The moral model says that disability is the result of the individual affected by impairment or his family's wrong behavior or $\sin .{ }^{4}$ I personally can also do something wrong and as a result I am afflicted with some form of impairment. Or one's parents did something wrong and as a result, one receives punishment in the form of a disability. There are those who think this model is on the wane. ${ }^{5}$ However, the author has seen evidences of this model during work in Africa, Europe, Central America and Asia. In Uganda, the author was often told by nationals that from a cultural perspective disability is seen as a direct result of someone being cursed in some way. In Ukraine, he was informed that disability was due to the "sins of the fathers" (reference to Exodus 34:7). Even in America, when a child with a disability is born to a family, as part of the grieving process a response can be, "What did I do to deserve this?" followed by intense selfexamination. ${ }^{6}$

But let's consider a Christian response to the moral model. In John 9 Jesus and his disciples come upon a man born blind. The disciples ask, "Rabbi, who sinned, this man or his parents, that he was born blind?" This perspective was not just that of the disciples but of the larger Jewish culture. We see this at the end of the passage, when the Pharisees say to the once blind man, "You were steeped in sin at birth..." an allusion to the fact that he was born blind and that sin was the cause of the disability. Jesus' response, however, is, "Neither this man nor his parents sinned but this happened that the works of God might be displayed in him." So we see from this passage that sin is not the cause of disability. Ostensibly, the blindness occurred according to God's purpose which is that "the works of God might be displayed in him." However, just for the sake of our discussion, let's assume that sin is the cause of disability. If we truly understood our sinful state as described in the Bible (Romans 3:10 \& 3:23 \& 5:12, Psalm 143:2 among other passages), and sin were the cause of disability, then we would expect all of our children to be disabled. That any child is born without disabilities means that sin is not the cause of disability.

This however, does not diminish the cultural reality of what people think and believe. The term "social construction" is sometimes used to understand cultural perspectives on an issue. ${ }^{7}$ So independent of a Biblical reality, if the socially constructed notion of disability in a particular culture is that it is the result of bad behavior, that will be the reality within that culture. Medical professionals have the ability to refute such claims and can attempt to replace them with a different narrative about what disability is.

Yet, these perspectives are deeply ingrained in people. In another situation, the author was providing training about a Biblical perspective on disability at a university outside of Kampala, Uganda. One of the students was a very bright man, who was physically disabled because of polio. He confided to the author, "I know that I am disabled because I contracted polio as a child. Intellectually, I know that. However, because of my enculturation, I cannot get out of my mind that I have been cursed. My culture tells me I have been cursed and it is very difficult to believe anything else." Even though his Christian faith told him otherwise, his enculturation and ongoing experience with culture was constantly at battle with both his scientific and Biblical understanding of why he was as he was.

Now, could someone do something of a sinful nature to cause another person or themselves to have a disability? Of course that is possible. Someone could inflict violence on another and disability could be the result. One could also engage in other behaviors leading to disability. However, the point here is that because one is a liar or a thief or has committed other personal sins, does not mean that the individual or his child will develop a disability.

\section{The Medical Model}

The term "medical model" should not be construed to be exclusively related to the medical profession. Anyone who seeks to improve people 
with impairments is employing the medical model. ${ }^{8}$ Wolf Wolfensberger the great American/Canadian disability theorist distinguished between bodily impairments (body, brain or sense organs) and resulting functional impairments (seeing, hearing, speaking, mobility, or self-care). ${ }^{9}$ Special education teachers, rehabilitation specialists, physicians, and even those who pray for healing for someone may be basing their understanding of impairment on the notion that the individual with the disability owns the disability, and interventions need to be aimed at fixing the individual. The idea is that impairment is not normal so our efforts seek to assist the person to become as normal as possible. This will hopefully not only attenuate the impact of one's impairment, but will also assist the person in becoming more socially accepted. You are repaired, and then reintegrated into society.

It may be that although the perceptions of disability are truly based upon it being considered atypical socially, in reality it is likely that it is relatively common but simply not accepted. Estimates range from $15-20 \%$ of population includes individuals with disabilities themselves. ${ }^{10}$ So the number of people actually impacted would be much larger. The social model of disability helps us to see there may be more to disability than an individual's personal characteristics.

\section{The Social Model}

The social model of disability basically states that disability is discrimination. ${ }^{11}$ Michael Oliver the British disability reformer has stated, "Disability is a social state and not a medical condition." 12 This notion is taken to the point of those with disabilities saying about themselves, "There is nothing at all wrong with me. The entire problem is society." Intuitively, there is a lot of truth in this perspective. Individuals with disabilities will often state that the most difficult part of having a disability is not the disability itself, but the manner in which you are treated if you have a disability. Clearly, there are impairments which are extremely difficult causing pain, etc. But largely, most disabilities are mild and people become acclimated to their impairment and learn to live on in spite of them.

Oliver thus concludes, "In our view, it is society which disables physically impaired people. Disability is something imposed on top of our impairments by the way we are unnecessarily isolated and excluded from full participation in society." 13

As mentioned above, societal discrimination may largely be determined by how disability has been socially constructed within a culture. If it has been constructed negatively, there will be negative implications to people having a particular characteristic. If it is constructed as simply typical, or within the normal range of being human, different societal responses will be experienced by those with disabilities.

\section{A Biblical Narrative}

A Biblical narrative has the potential to confront discriminatory, socially constructed narratives of disability. This narrative might include the following characteristics which would guide both the understanding of disability and the development of human supports. All people are created in the Image of God (Genesis 1:26). God will use people to accomplish Hs purposes, so in order to do so, $\mathrm{He}$ might create people with disabilities (Exodus 4:11). There is an intimacy described in the creation of people which implies purpose (Psalm 139:13). God desires people with disabilities to be in the church (Luke 14:12-14). Disability is not the cause of sin as stated above (John 9:3-4). There is purpose in "weaker" members in that they are indispensible to the Body of Christ (1 Corinthians 12:22-23). Faith and disability are not formulaic in that you may be a person of great faith like Paul and yet not be cured of a disability when you ask God to be healed (2 Corinthians 12:7). In summary, people with disabilities are created in the Image of God for a purpose because they are indispensible to the Body of Christ. Disability is not caused by personal sin or 
a lack of faith, but rather is part of God's purpose for humanity and his church. This Biblical narrative is very different from the societal narrative most often purveyed by societies. Through faith, we believe in God's sovereignty which implies purpose in disability.

\section{What is disability?}

So what is disability? It is likely a combination of the medical and social models. "Disability should not be reduced to a medical condition... Neither should it be reduced to an outcome of social barriers alone." ${ }^{\prime 14}$ From a Christian perspective one also sees God's sovereignty and purpose in disability. Yes, people do have characteristics called impairments, so there is a personal impairment aspect of disability. But there is concomitantly a social aspect of disability in that people really do experience discrimination because of their disability. However, it is an error to see disability as discrimination exclusively. As Shakespeare \& Watson (2002) point out, "If someone has an impairment that causes constant pain, how can the social environment be implicated?"14 Their point is that disability is both a personal and societal characteristic. It is personal impairment and it is societal discrimination.

Therefore, if one wanted to intervene in the lives of persons with disabilities, one would be best served by doing three things. First, one should address misconceptions which grow out of the moral model about the cause of disability, hopefully replacing them with a Christian understanding. Then, one should also attempt to impact the lives of persons having impairment to better their lives as much as possible. Finally, however, one should also focus significant effort at changing societal discrimination.

\section{The Responsibility of the Physician in Changing Societal Discrimination}

O'Brien \& O'Brien characterize the delivery of human services in the following manner.
When service providers set up programs to assist people who are excluded, they will often mindlessly follow this recipe:

- Group outsiders together

- Set them physically apart

- Isolate them socially

- Amplify stigma

- Arouse a sense of differentness

- Control the details of their lives

- Enforce material poverty as a condition of assistance

- Offer more benefits to those more like "one of us"

- Expect obedience and gratitude in return ${ }^{15}$

These criticisms might be leveled at human services just about anywhere. The good news is that services needn't be this way and the changes required are more attitudinally based than means based.

It is easy to see that O'Brien \& O'Brien's characterization is antithetical to inclusion in the community. This formula may too often reflect societal perceptions, particularly in third world places. It seems almost unavoidable that human services will develop such that people with disabilities are objectified and/or treated as if they were a commodity. Particularly in the West, but also elsewhere in the world, the resources spent and generated in the delivery of services to persons with disabilities can be distracting and dehumanizing. Income is distracting in that people are tempted to look away from supports genuinely needed which might be freely provided by the community rather than billed for by agencies. They are dehumanizing in that people become resource generators because of the problems they face in their lives. But it is not exclusively money that is used in this type of commerce. In Uganda, a woman told me of how a witch doctor told her he could easily cure her child with a disability if she lived with him as his sexual partner for a month. As desperate as she was, she consented and the result was a different kind of pain at the end of her month of being victimized. 
Professionals may unknowingly contribute to models that may be counterproductive. Human services are too often delivered in an unexamined fashion. Questions about how services are delivered may not be embraced or sought. As a result, change can be difficult if not impossible. Systems develop and peoples' jobs and incomes (legitimate or otherwise) are invested in the system remaining as it is. Too often one only discovers the flaws of human services when they submit themselves to them. ${ }^{16}$ All human service workers, but perhaps Christians especially, need to be as unwavering as possible in advocating for outcomes that will truly make a difference in peoples' lives. For example, Dr. Hans Reinders, a leading Dutch philosopher and theologian, has said in regard to persons with developmental disabilities, "The most important thing in life is friendships. And people in human services act as if they didn't know that." ${ }^{17}$ If we on the contrary do recognize that, then some of our efforts need to be faced internally, toward the agency for whom we are working to ensure that as a part of their efforts, they are facilitating relationships and friendships as an aspect of the care they are providing.

Dr. Richard Koch was a physician who was a pioneer in the treatment of persons with disabilities in America. In the 1970s he directed America's National Collaborative Study on Phenylketonuria (PKU). In part due to his efforts, children around the world are tested for PKU at birth as disability can largely be prevented through diet. He would often decry how persons with disabilities needed a program which was not their experience in America at that time. Because of his efforts and others like him, human services leading to the right to a public school education developed in the United States for those with developmental disabilities.

Human services have the potential to move society to the next stage of community inclusion of persons with disabilities. However, human services must be developed that are not exclusively medical model based. This is not always intuitive as medical model-based solutions are most often developed by the professional for people in need. The thought of including outside agents as a part of an intervention is probably not how professionals have been educated to think in the diagnosis of problems and prescription of solutions. Yes, a social environment that is changed to reflect the love of Christ towards all people is highly desirable. However, social connections that reduce discrimination and invite friendship, whatever their motivation, are also desirable. In each of these areas, social model approaches invite the social environment to play a role supporting individuals with disabilities. A good medical system will seek to develop supports within the community such that people do not rely exclusively on medical providers.

\section{Conclusions}

The degree to which segregation is the outcome of human supports (medical or otherwise) is the degree to which it needs to be changed. The major focus of all human services should be community development in terms of creating a socially inclusive community. We do not ignore impairments in individuals, but provide medical model supports as appropriate. However, concomitantly we invest major effort into what might be called social model interventions. Interventions are aimed at assisting people to do the right thing toward those with disabilities. Professionals focus efforts on facilitating the development of real friendships in their own lives and those of community members.

Physicians, as community leaders, are in a unique position to encourage social change. They can facilitate change through their professional work in their goals, design of service delivery, broadened notions of intervention which include community engagement and developing relationships, and criteria for evaluation of services. They can also facilitate change in their personal lives through community participation, personal relationships with devalued people, and advocacy. 


\section{References}

1. Kaplan, D. The definition of disability [Internet]. The Center for an Accessible Society; [cited 2015 September 20]. Available from http://www.accessiblesociety.org/topics/demographi cs-identity/dkaplanpaper.htm

2. ADA National Network (nd) What is the definition of disability under the ADA? Available from https://adata.org/faq/what-definition-disabilityunder-ada

3. World Health Organization. (2001). International classification of functioning, disability and health: Short version. Geneva, Switzerland: World Health Organization (p. 28).

4. Altmaier, E. \& Hansen, J. (eds.), (2012). The Oxford Handbook of Counseling Psychology. NY, NY: Oxford University Press.

5. Wasserman, D., Asch, A., Blustein, J. \& Putnam, D., (2011). Disability: Definitions, Models, Experience. In Stanford Encyclopedia of Philosophy. Available from http://plato.stanford.edu/entries/disability/

6. Kubler-Ross, E. \& Kessler, D. (2005). On Grief and Grieving: Finding the Meaning of Grief through the Five Stages of Loss. NY, NY: Scribner.

7. Berger, P. \& Luckman, T. The social construction of reality. Middleton, Great Britain: Penguin Books; 1966.

8. Altmaier, E. \& Hansen, J. (eds.), (2012). The Oxford Handbook of Counseling Psychology. NY, NY: Oxford University Press.

9. Wolfensberger, W. (1998). A brief introduction to Social Role Valorization: A high-order concept for addressing the plight of societally devalued people and for structuring human services $\left(3^{\text {rd }}\right.$. ed.). Syruacus, NY: Training Institute for Human Service Planning, Leadership \& Change Agentry (Syracuse University).

10. World Health Organization, (2011). World Report on Disability. Geneva, Switzerland: World Health Organization.
11. Altmaier, E. \& Hansen, J. (eds.), (2012). The Oxford Handbook of Counseling Psychology. NY, NY: Oxford University Press.

12. Oliver, M. The individual and social models of disability. Presented at: Joint Workshop of the Living Options Group and the Research Unit of the Royal College of Physicians; 1990 July 23; [cited 2015 September 20]. Available from http://www.leeds.ac.uk/disabilitystudies/archiveuk/Oliver/in\%20soc\%20dis.pdf

13. Oliver, M. Understanding disability: from theory to practice. Basingstoke: Macmillan, 1996. P. 22.

14. Shakespeare, T and Watson, N. The social model of disability: an outdated ideology? Research in Social Sciences and Disability 2002; 2: 9-28. http://dx.doi.org/10.1016/S1479-3547(01)80018-X [cited 2015 September 20]. Available from http://disabilitystudies.leeds.ac.uk/files/library/Shakespeare-socialmodel-of-disability.pdf

15. O'Brien, J \& O'Brien, C. Members of each other: Perspectives on social support for people with severe disabilities. In Nisbet, $\mathbf{J}$ (ed.) Natural supports in school, at work, and in the community for people with severe disabilities. Baltimore, MD: Brookes; 1992. p. 17-63.

16. Basnett, I. Health care professionals and their attitudes toward and decisions affecting disabled people. In Albrect, Seelman \& Bury (eds.), Handbook of Disability Studies. Thousand Oaks, CA: Sage Publications; 2001. p. 450-467.

17. Reinders, H S. The power of inclusion and friendship. Presented at: $35^{\text {th }}$ Annual Meeting of the American Association on Intellectual and Developmental Disabilities; 2011 June 9; St. Paul, MN.

Peer Reviewed

Competing Interests: None declared.

Correspondence: Jeff McNair, California Baptist University, United States. jmcnair@joniandfriends.org

Cite as: McNair J. Disability and human supports. Christian Journal for Global Health (Nov 2015), 2(2):10-15.

(c) McNair J This is an open-access article distributed under the terms of the Creative Commons Attribution License, which permits unrestricted use, distribution, and reproduction in any medium, provided the original author and source are properly cited. To view a copy of the license, visit http://creativecommons.org/licenses/by/3.0/ 